\title{
Insulin and the regulation of protein synthesis in muscle
}

By IrA G. Wool, Departments of Physiology and Biochemistry, University of Chicago, Chicago, Illinois 60637, USA

\section{Introduction}

Diabetic animals and patients are unable to regulate their protein metabolism in a normal manner, although their response to the disease - an acceleration of protein catabolism and a severe restriction of protein synthesis - is appropriate to their precarious metabolic state. The diabetic animal needs calories, and especially it needs glucose, so it is expedient for the animal to sacrifice protein to satisfy its requirements. The diabetic syndrome includes then a negative nitrogen balance and wasting of muscle as reflections of the alterations of protein metabolism. In ordinary circumstances insulin dampens protein breakdown and stimulates its synthesis. The mechanism by which the hormone does so is not known.

I should emphasize at the outset that there is no evidence for a direct effect of insulin on the ribosome or any of its functional appendages. Indeed, Cuatrecasas (r 969) has shown that insulin need not enter the adipocyte in order to accelerate glucose transport into the cell. If the results are applicable to all cells and all the biological actions of the hormone, then an analysis of the effect of insulin on ribosome function is not likely to yield information on its primary action. But it must be clearly recognized that what has been shown is that insulin need not enter the adipose cell to mediate the membrane (or transport) actions of the hormone. It remains to be determined if the anabolic effects of insulin (the synthesis of macromolecules) can occur without its entry into the cell. If insulin does not enter the muscle cell then it must generate some intermediate which acts as its deputy in the modulation of protein synthesis.

In the cause of brevity, and to simplify the presentation, I assume the following: the effect of insulin on protein synthesis is independent of the action of the hormone on glucose or amino acid transport (Wool, 1964, 1965, 1968; Wool \& Scharff, 1968). Most will probably accept the first part without demur. We realize there are not a few who might still contest the second part (Hider, Fern \& London, 1971). The experimental findings that support the assumptions have been reviewed before (Wool, I964, I965, 1968; Wool \& Scharff, r968).

\section{Insulin and ribosome function}

Ribosomes from the muscle of diabetic rats synthesize less protein than normal (Wool \& Cavicchi, 1967). On the other hand, the administration of small amounts 
of insulin (as little as $4 \mu \mathrm{g}$ ) to diabetic animals will rapidly increase the synthesis of protein by ribosomes (only $5 \mathrm{~min}$ is required). Insulin will increase the synthesis of protein by ribosomes and mediate the assembly of polysomes even in diabetic animals pretreated with actinomycin (Stirewalt, Wool \& Cavicchi, 1967). That is to say, the action of the hormone is seen in the absence of DNA-dependent RNA synthesis. That obscrvation implies the hormone increases protein synthesis in the absence of the synthesis of new ribosomes or of mRNA; that in turn can only mean that there is in the muscle of diabetic animals a reservoir of $\mathrm{mRNA}$, a reservoir that is not utilized. Insulin presumably conditions the binding and translation of that preformed mRNA, accounting in that way for the assembly of polysomes and the increase in protein synthesis.

The question then is the nature of the insulin-mediated change that leads to an alteration in the ability of ribosomes to translate mRNA. We had quite early on made an observation that was to prove important. The difference in the capacity of normal and diabetic ribosomes to synthesize polyphenylalanine (polyphe) in the presence of polyuridylic acid (poly $\mathrm{U}$ ) was critically dependent on the magnesium concentration (Wool, Stirewalt, Kurihara, Low, Bailey \& Oyer, 1968; Castles, Rolleston \& Wool, 1971). At high-magnesium concentrations diabetic ribosomes synthesized more polyphe than normal, whereas at low concentrations the reverse was true. The greater synthesis of polyphe we believe to be the secondary consequence of diabetic ribosomes having less mRNA and as a result being able to bind more poly $\mathrm{U}$ in the favorable circumstances provided by a high concentration of magnesium. If diabetic ribosomes bind more poly $U$ they will synthesize more polyphe, all other things being equal. Therefore, we focused attention on the results at low-magnesium concentrations as more nearly reflecting the physiological condition.

The decreased capacity of diabetic ribosomes to translate poly $U$ at low concentrations of magnesium might be due to decreased binding of phenylalanyl-tRNA (Phe-tRNA); at least the possibility seemed worth testing. We compared the ability of normal and diabetic ribosomes to bind Phe-tRNA in the absence of enzyme (Castles et al. I97I) and in the reaction catalysed by aminoacyltransferase I (T-I) (Leader, Wool \& Castles, I97I). At almost any magnesium concentration the amount of Phe-tRNA bound in the absence of ' $T$ - $I$ is trivial when compared with the enzymecatalysed reaction (Leader et al. I97I). A more important finding was that diabetic ribosomes did in fact bind less Phe-tRNA than normal ribosomes at low concentrations of magnesium and more at high concentrations. Thus the binding of PhetRNA closely parallels the translation of poly $U$.

The functional significance of binding of aminoacyl-tRNA to ribosomes can only be assessed when the product of the reaction is known (Castles et al. 1971; Leader et al. 1971). For that reason we analysed the radioactive material bound to ribosomes by isolating the particles, subjecting them to alkaline hydrolysis, and then analysing the hydrolysate by paper chromatography. When ribosomes were incubated in $7.5 \mathrm{mmol}$ magnesium - the concentration at which the diabetic defect in binding of Phe-tRNA was seen - almost all of the radioactive material bound to the ribosome remained at the origin on paper chromatograms. Little phenylalanine was recovered. 
What is more, the difference in the amount of origin material accounted for the difference in binding to normal and diabetic ribosomes. We recognized the importance of determining the nature of the origin material. In the chromatographic system that we used, homopolymers of phenylalanine with a chain length of five or greater will remain at the origin. However, our failure to detect diphenylalanine or triphenylalanine made it unlikely the origin material was oligophenylalanine. But the ribosomes we used contain nascent peptide chains, that is peptidyl-tRNA; in addition, the peptide bond-forming enzyme, peptidyl transferase, is a component of the ribosome. Thus it seemed possible that the radioactive Phe-tRNA bound to the ribosome was incorporated into the carboxyl-terminus of nascent chains. To test this possibility the origin material was subjected to hydrazinolysis (Castles et al. I97I). (The heating of proteins in hydrazine causes transamidation of all peptide bonds to hydrazides; only the carboxyl-terminal amino acid is liberated as free $\alpha-$ amino- $\alpha$-carboxylic acid.) Some $97 \%$ of the radioactivity of the origin material was recovered as free $\left[{ }^{14} \mathrm{C}\right]$ phenylalanine $\left(\left[{ }^{14} \mathrm{C}\right] \mathrm{Phe}\right)$ after hydrazinolysis, indicating that the origin material was nascent peptide with a single carboxyl-terminal $\left[{ }^{14} \mathrm{C}\right]$ Phe.

It would appear that at low concentrations of magnesium, and in the absence of specific initiation factors, aminoacyl-tRNA (AA-tRNA) is bound only to ribosomes that carry peptidyl-tRNA and no initiation of protein synthesis occurs. Rather, AA-tRNA is bound to the acceptor site of those ribosomes that have peptidyl-tRNA in the donor site, a peptide bond is synthesized, and the nascent chain is elongated by one amino acid. The new peptide is transferred to the acceptor site and no further binding can take place. A consideration of the observations provides us with a possible explanation for the difference in function of normal and diabetic ribosomes; namely that preparations of normal ribosomes have more peptidyl-tRNA than diabetic ribosomes and that peptidyl-tRNA is necessary for binding AA-tRNA at low concentrations of magnesium. We knew from experiments with puromycin that a greater percentage of ribosomes in a normal preparation have peptidyl-tRNA bound to them (Wool \& Kurihara, 1967).

The observations also provide a possible explanation for the difference in function of normal and diabetic $60 \mathrm{~S}$ subunits (Martin \& Wool, r968), namely that normal 6oS subunits have more peptidyl-tRNA than diabetic $60 \mathrm{~S}$ subunits and that peptidyltRNA allows protein synthesis to occur at low concentrations of magnesium. Some peptidyl-tRNA does remain bound to the $60 \mathrm{~S}$ subunit when ribosomes are dissociated (Stirewalt, Castles \& Wool, I97 I). I emphasize that while the explanation is plausible, I am not sure that it is sufficient to account entirely for the difference in function of normal and diabetic ribosomes or normal and diabetic $60 \mathrm{~S}$ subunits.

The problem then is to account for the decrease in peptidyl-tRNA on diabetic ribosomes. It seems reasonable that it might result from a defect in muscle cells in the capacity for the initiation of endogenous protein synthesis, a possibility considerably reinforced by the finding of increased numbers of ribosome subunits in the muscle of diabetic animals (Rannels, Jefferson, Hjalmarson, Wolpert \& Morgan, I970). The decisive question then is whether there is an intrinsic difference between normal and diabetic ribosomes or whether they are distinguished only by the amount 
of attached peptidyl-tRNA (indeed, one might say by the amount of peptidyl-tRNA with which they are contaminated).

\section{The translation by normal and diabetic ribosomes of polyuridylic acid and $R N A$ extracted from encephalomyocarditis virus (EMC RNA)}

In an attempt to obtain answers to the questions posed above, we have for a time been engaged in an effort to compare the capacity of normal and diabetic ribosomes to initiate the synthesis of proteins as distinct from the elongation of peptide chains actually started in the cell. We were aware, as are all those who work seriously on the problem, that the use of cell-free systems to study the control of protein synthesis is greatly facilitated when natural mRNA is available. One need only contemplate the magnificent progress that has come from the use of bacteriophage RNA. What is more, it is so obvious as to be trivial that the most economical way to regulate protein synthesis is to control the initiation of peptide chains. It makes far more sense than to cause queuing in the midst of the synthesis of a chain (as would occur if elongation were controlled), or to cause a hold-up at chain termination. Ideally, the study of initiation of protein synthesis would make use of natural (i.e. cellular) mRNA, but that is not so easy to come by. The next best alternative is viral mRNA. The RNA extracted from encephalomyocarditis virus when added to mammalian ribosomes will stimulate protein synthesis; moreover, the synthesis of virus-specific peptides is carried out with fidelity (Matthews, I970; Mathews \& Korner, 1970). We have established that in strictly defined conditions, and I shall give those conditions in a moment, normal and diabetic muscle ribosomes will also translate EMC RNA with fidelity, for the peptides synthesized in vitro correspond to the proteins synthesized in EMC-infected cells.

Translation of EMC RNA requires ribosomes. We have used ribosomes reconstituted from subunits. Ribosomal subunits are prepared by treating normal and diabetic ribosomes with puromycin in $0.8 \mathrm{M}-\mathrm{KCl}$. The antibiotic removes nascent peptide from the ribosomes; the high concentrations of salts remove initiation factors. Thus we believe the subunits to be relatively pure (i.e. free of non-ribosmal contaminants). Ribosomes formed from subunits have no endogenous activity, that is to say they do not synthesize protein unless an exogenous template is added.

The translation of EMC RNA also requires ascites cell supernatant. The cytosol from no other cell - muscle, liver and so on - will do. The reason is that the supernatant from ascites cells contain all three initiation factors $\left(M_{1}, M_{2}\right.$, and $\left.M_{3}\right)$; supernatant from other tissues has only MI (Leader, Klein-Bremhaar, Wool \& Fox, I972). I might point out that ascites supernatant fraction (like that from other tissues) also contains the other two factors required for protein synthesis, T-I and T-II.

The following are also required for assay of EMC RNA translation: ATP and an energy-generating system (creatine phosphate and creatine phosphokinase); twenty amino acids of which one is radioactive, $\left[{ }^{3} \mathrm{H}\right]$ phenylalanine ([$\left[{ }^{3} \mathrm{H}\right] \mathrm{Phe}$ ); buffer; $\mathrm{KCl}$; and, most critically, $5 \mathrm{mmol}$ magnesium, because at higher concentrations of the cation the need for initiation factors is obviated; and finally EMC RNA. Actually, we have used a second template, poly U. At $5 \mathrm{mmol}$ magnesium, two of 
the three initiation factors, $\mathrm{M}_{\mathbf{I}}$ and $\mathrm{M}_{2}$, are required for optimum synthesis of polyphe (Shafritz \& Anderson, 1970).

Diabetic ribosomes reconstituted from subunits are less efficient than normal in the translation of either poly U or EMC RNA (Table I). I wish to emphasize the following points: the experiments are carried out in circumstances where the synthesis of protein requires the initiation of new peptide chains; that EMC RNA is translated with fidelity for virus-specific peptides are synthesized; and that the initiation factors are added to normal and diabetic ribosomes in equal amounts from an indifferent source (ascites cells). The results then would indicate that diabetic ribosomes suffer a defect that renders them less capable than normal ribosomes of using those factors to initiate the synthesis of proteins. But I hasten to submit a caveat. It remains still to be established that the difference I have just described is intrinsic to the ribosome rather than carried by some fortuitous contaminant unequally distributed between normal and diabetic ribosomal subunits - just as unequal amounts of peptidyl-tRNA on normal and diabetic ribosomal subunits account for the apparent difference in their ability to bind AA-tRNA.

Table 1. Translation of polyuridylic acid and EMC RNA by normal and diabetic ribosomes reconstituted from subunits

\begin{tabular}{lcc} 
Template & {$\left[{ }^{3} \mathrm{H}\right]$ phenylalanine incorporated into protein } \\
& \multicolumn{3}{c}{ (pmol) } & Diabetic \\
None & Normal & 0.03 \\
Poly U & 0.04 & $86.4(-48 \%)$ \\
EMC RNA & 89.4 & $0.52(-40 \%)$
\end{tabular}

EMC RNA, RNA extracted from encephalonyocarditis virus; poly $\mathrm{U}$, polyuridylic acid.

\section{Formation of an initiation complex by normal and diabetic ribosomes}

There is a factor ( $40 \mathrm{~S}$ binding factor or $4 \mathrm{OS} \mathrm{BF}$ ) in the supernatant of muscle and liver cells which catalyses the binding of Phe-tRNA to $40 \mathrm{~S}$ subunits (Leader, Wool \& Castles, 1970 ). It now seems likely that the $40 \mathrm{~S} \mathrm{BF}$ and $\mathrm{MI}_{\mathrm{I}}$ are one and the same (Leader \& Wool, I972). We suspected from the beginning that the $40 \mathrm{OS}$ BF would catalyse the formation of an initiation complex containing the $40 \mathrm{~S}$ subunit, the template, AA-tRNA, and perhaps the $40 \mathrm{OS} \mathrm{BF}$ itself. What is more, it seemed likely that the initiation complex would be an obligatory intermediate in the reassociation of ribosomal subunits. Thus the $40 \mathrm{~S} \mathrm{BF}$ should catalyse the formation of $80 \mathrm{OS}$ monomers from 40 and $60 \mathrm{~S}$ ribosomal subunits. We tested those predictions by incubating subunits in buffer containing $3.5 \mathrm{mmol} \mathrm{MgCl} 2$ and $80 \mathrm{mmol} \mathrm{KCl}$, in which circumstances no reassociation ordinarily takes place (Wettenhall, Leader \& Wool, I97r). Addition of a preparation of the $40 \mathrm{~S} \mathrm{BF}$ along with the other components leads to formation of a considerable number of $80 \mathrm{~S}$ monomers. We (Wettenhall and Wool, unpublished observations) have now tested the ability of normal and diabetic ribosomal subunits to participate in the reassociation reaction catalysed by the initiation factor preparation. Diabetic ribosomes are less effective than normal in the reassociation reaction, and what is more, the defect is carried by the $60 \mathrm{~S}$ subunit $31(2) 8$ 
(Fig. $x$ ). We find the observation exciting, but once again understand that caution is the prudent attitude.

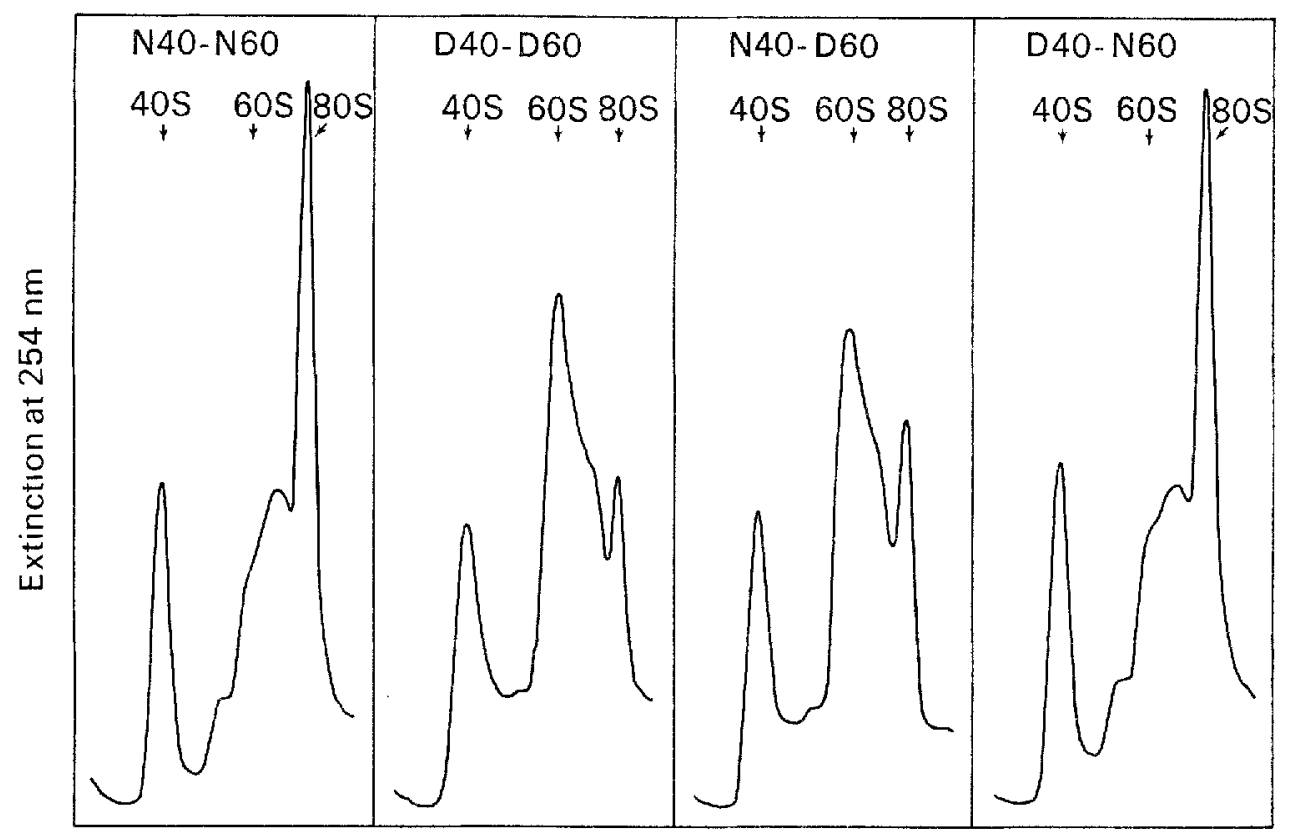

Fig. 1. Reassociation of normal and diabetic ribosomal subunits. The assay was carried out as described by Wettenhall et al. (r97I). $N_{40}, 40 \mathrm{~S}$ ribosomal subunits from skeletal muscle of normal rats; $N 60,60 \mathrm{~S}$ ribosomal subunits from skclctal muscle of normal rats; D60, $40 \mathrm{~S}$ ribosomal subunits from skeletal muscle of alloxan-diabetic rats; D60, $60 \mathrm{~S}$ ribosomal subunits from skeletal muscle of alloxan-diabetic rats.

\section{Conclusion}

There are two fundamental ways to increase synthesis of protein: by initiating the transcription of mRNA; or by accelerating the translation of preformed mRNA. Insulin and diabetes affect the latter. Ribosomes have generally been considered to be non-specific machinery that can be programmed to synthesize any protein provided the proper tape (i.e. mRNA) is supplied. That view implies a static ribosome. Common wisdom has it that regulation of the translation of mRNA is most likely to be achieved by conditioning the availability or activity of initiation factors. We accept that likelihood. We propose an additional mechanism: its essence is a malleable or dynamic ribosome, a particle whose structure and hence function can be changed so as to moderate protein synthesis. One can imagine a number of ways in which the structure and function of ribosomes might be altered: by addition or deletion of proteins which are not essential for function but amplify ribosome activity (Kurland, I970); by chemical modification of ribosomal proteins, as, for example, phosphorylation (Eil \& Wool, r971) or acetylation; by a change in the conformation of a ribosomal protein; or in the structure or order of the ribosome itself. Specifically, we suggest that a consequence of diabetes and of insulin action may be an alteration of the structure of muscle ribosomes such that the ability of the particle to initiate 
protein synthesis is changed. The nature of the putative change in the ribosome and how it is effected by insulin are unsolved problems.

\section{REFERENCES}

Castles, J. J., Rolleston, F. S. \& Wool, I. G. (I971). F. biol. Chem. 246, 1799.

Cuatrecasas, P. (1969). Proc. natn. Acad. Sci. U.S.A. 63, 450.

Eil, C. \& Wool, I. G. (1971). Biochem. biophys, Res. Commun. 43, 100I.

Hider, R. C., Fern, E. B. \& London, D. R. (197I), Biochem. f. 125, 75 I.

Kurland, C. G. (1970). Science, N.Y. I69, I17I.

Leader, D. P., Klein-Bremhaar, H., Wool, I. G. \& Fox, A. (x972). Biochem. biophys. Res. Commun. 46, 215.

Leader, D. P. \& Wool, I. G. (1972). Biochim. biophys. Acta 262, 360.

Leader, D. P., Wool, I. G. \& Castles, J. J. (1970). Proc. natn. Acad. Sci. U.S.A. 67, 523.

Leader, D. P., Wool, I. G. \& Castles, J. J. (т97I). Biochem. F. 124, 537.

Martin, T. E. \& Wool, I. G. (1968). Proc. natn. Acad. Sci. U.S.A. 60, 569.

Mathews, M. B. (1970). Nature, Lond. 228, 66r.

Mathews, M. B. \& Korner, A. (1970). Eur. 7. Biochem. 17, 328.

Rannels, D. E., Jefferson, L. S., Hjalmarson, A. C., Wolpert, E. B. \& Morgan, H. E. (1970). Biochem. biophys. Res. Commun. 40, I I 10.

Shafritz, D. A. \& Anderson, W. F. (1970). F. biol. Chem. 245, 5553 .

Stirewalt, W. S., Castles, J. J. \& Wool, I. G. (197 I). Biochemistry, Easton 10, 1594.

Stirewalt, W. S., Wool, I. G. \& Cavicchi, P. (1967). Proc. natn. Acad. Sci. U.S.A. 57, 1885.

Wettenhall, R. E. H., Leader, D. P. \& Wool, I. G. (1971). Biochem. biophys. Res. Commun. $43,994$.

Wool, I. G. (1964). In Action of Hormones on Molecular Processes p. 422 [G. Litwack and D. Kritchevsky, editors]. New York: Wiley.

Wool, I. G. (1965). Fedn Proc. Fedn Am. Socs exp. Biol. 24, 1о6о.

Wool, I. G. (1968). In Protein and Polypeptide Hormones p. 285 [M. Margoulies, editor]. Amsterdam: Excerpta Medica Foundation.

Wool, I. G. \& Cavicchi, P. (1967). Biochemistry, Easton 6, I231.

Wool, I. G. \& Kurihara, K. (1967). Proc. natn. Acad. Sci. U.S.A. 58, 2401.

Wool, I. G. \& Scharff, R. (1968). In Protein Nutrition and Free Amino Acid Patterns p. I57 [J. H. Leathem, editor]. New Brunswick: Rutgers University Press.

Wool, I. G., Stirewalt, W. S., Kurihara, K., Low, R. B., Bailey, P. \& Oyer, D. (rg68). Recent Prog. Horm. Res. 24, 139. 